\begin{tabular}{|l|l|}
\hline $\begin{array}{l}\text { ESCOLA DE COMUNICAÇÃO, } \\
\text { ARTES E DESIGN } \\
\text { FUCRS }\end{array}$ & $\begin{array}{l}\text { FAMECOS } \\
\text { mídia, cultura e tecnologia } \\
\text { Revista FAMECOS, Porto Alegre, v. 27, p. 1-16, jan.-dez. } 2020 \\
\text { e-ISSN: 1980-3729 | ISSN-L: 1415-0549 }\end{array}$ \\
\hline https://dx.doi.org/10.15448/1980-3729.2020.1.38273
\end{tabular}

JORNALISMO

\title{
As fontes populares na cobertura sobre segurança da CBN Rio
}

\author{
The popular sources in CBN Rio's safety coverage \\ Las fuentes populares en la cobertura de seguridad de CBN Rio
}

\author{
Luãn José Vaz Chagas ${ }^{1}$ \\ 0000-0002-2491-8479 \\ luaanchagas@gmail.com
}

Recebido em: 25/5/2020.

Aprovado em: 4/11/2020.

Publicado em: 7/01/2021.

\section{(c) (1)}

Artigo está licenciado sob forma de uma licença Creative Commons Atribuição 4.0 Internacional.
Resumo: O artigo realiza uma análise sobre a interação com os ouvintes no radiojornalismo da CBN Rio do Janeiro na temática de segurança e como o cidadão comum é selecionado a partir da complexificação da ideia de fonte popular para o noticiário local. Utiliza-se a perspectiva multimetodológica com a coleta dos áudios do programa ao longo de uma semana ao lado de uma observação sistemática e de entrevistas com os profissionais da emissora com foco na forma de confiabilidade exercida e os valores compartilhados pelos jornalistas na escolha das vozes. Diferencia os conceitos de interação, acesso e participação, bem como as variáveis que levam à ausência do cidadão comum, mesmo com acesso a plataformas oriundas da cultura digital.

Palavras-chave: Fontes. Rádio expandido. Radiojornalismo. Segurança. Cidadão comum.

Abstract: The article analyzes the interaction with listeners in the radiojournalism of CBN Rio de Janeiro on the security theme and how the common citizen is selected from the complexification of the popular source's concept for the local news. The multi-methodological perspective is used to collect the audios of the program over the course of a week along with a systematic observation and interviews with the professionals of the station, focusing on the form of reliability exercised and the values shared by the journalists in the choice of voices. It differentiates the concepts of interaction, access and participation, as well as the variables that lead to the absence of the common citizen even with access to platforms from the digital culture.

Keywords: Sources. Expanded radio. Radiojournalism. Safety. Ordinary citizens.

Resumen: El artículo analiza la interacción con los oyentes en el periodismo radial de CBN Rio de Janeiro sobre temas de seguridad y cómo se selecciona al ciudadano común a partir de la complejidad de la idea de una fuente popular de noticias locales. La perspectiva multimetodológica se utiliza con la recopilación de los audios del programa durante una semana junto con la observación sistemática y las entrevistas a los profesionales de la emisora centradas en la forma de confiabilidad ejercida y los valores compartidos por los periodistas en la elección de voces. Diferencia los conceptos de interacción, acceso y participación, asi como las variables que conducen a la ausencia del ciudadano común, incluso con acceso a plataformas provenientes de la cultura digital.

Palabras clave: Fuentes. Radio expandida. Periodismo radial. La seguridad. Ciudadanos comunes.

\section{Introdução}

A preferência pelas fontes oficiais, especializadas e institucionais são partes de uma dinâmica estruturada no modelo profissional jornalístico já apontado por autores como Hall et al. (1999), Lage (2001), Pinto (2000), 
Gans (1980), Schmitz (2011), Traquina (2005), Manning (2001) e Franklin (2011). Na lógica apontada pelos autores, as fontes populares são encaixadas em formas de interação que priorizam respostas buscadas de antemão pelos jornalistas, sem a possibilidade de ressonância de seus argumentos, muitas vezes acionada por uma variável circunstancial que depende diretamente da importância da informação e como ela impactará o noticiário (REICH, 2015). Diante desse cenário, como se dá a construção das notícias pela ótica do cidadão ou da cidadã comum na cobertura sobre segurança pública no estado do Rio de Janeiro?

O gatewatching complexifica essa relação ao deslocar para o papel do público uma função importante na curadoria colaborativa realizada pelos jornalistas no momento da construção da notícia (BRUNS, 2011). A seleção diversa e múltipla em uma redação é exercida junto a fontes profissionalizadas e não profissionalizadas, mantendo características do gatekeeping na escolha e apuração junto a diferentes agentes da sociedade (SHOEMAKER; VOS, 2011). A interação torna o ambiente dinâmico e difuso, configurando o ouvinte como uma fonte na programação (LOPEZ, 2010). Algo que garantiria o acesso habitual e não o conceito de participação em sua plenitude defendido por Carpentier (2012). Em outro caminho, Reich $(2011,2015)$ argumenta que mesmo com as novas formas de comunicação instantânea por mecanismos oriundos da cultura digital, a ausência do cidadão comum dos debates jornalísticos ainda é uma realidade no momento da seleção e encaixe temático que realizam os jornalistas no cotidiano.

A partir desse contexto, o artigo realiza uma análise multimetodológica sobre a interação com os ouvintes no programa local da CBN do Rio de Janeiro na temática de segurança. Buscamos verificar como o cidadão comum é acionado com a complexificação da ideia de fonte popular no noticiário. Ao lado da análise de conteúdo realizada de 13 a 17 de agosto de 2018, também foram utilizados como protocolo de coleta de dados a observação sistemática na redação da emissora e entrevistas semiestruturadas com cinco jornalistas que atuam na redação em processos de decisão e seleção das fontes via mecanismos digitais instantâneos como WhatsApp, Telegram, Facebook e Twitter.

Os resultados evidenciam estratégias de dependência dos setores oficiais que fazem parte da hierarquia da credibilidade, enquanto os cidadãos comuns ainda são relegados a papéis secundários. $O$ acesso ainda é pequeno frente aos diferentes tipos de fonte e se torna apenas circunstancial enquanto são priorizadas as vozes oficializadas da sociedade em detrimento da construção diversa e plural sobre a temática. É possivel verificar nesse sentido, uma ampliação do discurso policial e jurídico sobre questões como operações em comunidades e a restrição dos relatos humanos como parte dos argumentos de fontes populares sem apontamentos com alternativas para as políticas de segurança no Estado.

\section{O cidadão comum como fonte popular no radiojornalismo}

Os dados sobre segurança pública e violência no Brasil demonstram a importância que o tema ganhou nas últimas duas décadas em meio ao ambiente de crise econômica e política em niveis globais. Exemplo disso está no Atlas da Violência de $2018^{2}$ do Instituto de Pesquisa Econômica Aplicada (Ipea) realizado em conjunto com o Fórum de Segurança Pública que registrou um aumento de 38.929 homicidios em 1996 para 62.517 em 2016. A taxa de 30,3 mortes por cem mil habitantes foi atingida pela primeira vez no Brasil. Outra questão que impressiona são as mortes de negros, com 40,2 por 100 mil habitantes, enquanto as de não negros estão em menos da metade, 16,0.

A juventude é a principal vítima nos homicidios como apontam os dados de 2016 fornecidos pelo Ministério da Saúde para a pesquisa. Somente nesse ano foram 33.590 assassinatos com 94,6\% do sexo masculino. Entre os estados mais violentos estão Sergipe com 64,7 homicídios por 100 mil habitantes, o Acre com 54,2. O Rio de Janeiro

2 Atlas da Violência de 2018. Disponivel em: http://www.ipea.gov.br/atlasviolencia/dados-series/17. Acesso em: 15 jul. 2020. 
aparece atrás com 36,38, porém em números totais chega ao segundo lugar com 6.053 mortes no ano da pesquisa, enquanto o estado da Bahia lidera com 7.171. Por outro lado, é em terras fluminenses onde a polícia mais mata no Brasil, com 538 pessoas mortas em decorrência de conflitos ou ações das forças de segurança do Estado.

Em 2018, o Decreto número 9.288, de 16 de fevereiro ${ }^{3}$ do mesmo ano, dava início à "intervenção federal no Estado do Rio de Janeiro com o objetivo de pôr termo ao grave comprometimento da ordem pública" (BRASIL, 2018). A ação aprovada pela Câmara dos Deputados e pelo Senado por meio do Decreto Legislativo número $10,{ }^{4}$ de 20 de fevereiro de 2018, foi finalizada no dia 31 de dezembro de 2018, como previa o governo de Michel Temer (MDB). Segundo os relatórios e dados do Centro de Estudos de Segurança e Cidadania da Universidade Candido Mendes (CESeC/Ucam) que instituiu o Observatório da Intervenção, ${ }^{5}$ o número de tiroteios cresceu $57 \%$ durante o período e apenas $6 \%$ da verba destinada (R\$ 72 milhões) foi devidamente utilizada, enquanto R $\$ 61$ milhões ficaram com as Forças Armadas. Ao todo, foram gastos R\$ R\$121.251.783,006 que, de acordo com o Observatório, não resultaram em efeitos práticos e aumentaram a sensação de insegurança.

A prova para isso estaria nos 206 casos de violências e violações, confrontos e balas perdidas. Já o Relatório de Pesquisa intitulado A intervenção federal no Rio de Janeiro e as organizações da sociedade civil publicado por Rodrigues e Armstrong (2019, p. 39) aponta que aumentou o número de homicídios decorrentes de ação policial no estado com o recorde de 1.532 mortes no ano de 2018 contra os 538 em 2016. As autoras ainda argumentam que:

as narrativas da imprensa sobre as operações GLO [Garantia da Lei e da Ordem] permitiram concluir que as forças armadas assimilaram a política do confronto que vem sendo posta em prática no estado nos últimos anos e que tem resultado em números extremamente elevados de homicidios por intervenção policial, muito embora sem fazer cair suficientemente os principais indicadores de violência e crime (RODRIGUES; ARMSTRONG, 2019, p. 39).

Ainda no caso do Rio de Janeiro, pesquisa divulgada em março de $2018^{7}$ pelo Fórum de Segurança Pública em conjunto com o Instituto Datafolha demonstrou que em um universo de 1.012 entrevistados, mesmo com o apoio de $76 \%$ entre os participantes da pesquisa, $69 \%$ destes continuavam com a sensação de insegurança e achavam "que a presença do Exército não fez diferença alguma" (DATAFOLHA, 2018). O medo era concentrado em balas perdidas (92\%), serem feridos ou mortos em assaltos (92\%), ficar no meio de um tiroteio (92\%), morrer assassinado (87\%), ter sua casa invadida ou roubada (84\%) e sofrer violência da Polícia Militar (70\%).

Diante desse cenário, a construção das noticias sobre a temática se torna um espaço de discussão pública sobre as alternativas em políticas públicas e ações do Estado. Por outro lado, as fontes que participam do debate não possuem as mesmas condições de acesso ao jornalismo como um ambiente de disputa entre diferentes alternativas (CHAPARRO, 1994). De acordo com Molotch e Lester (1999) podemos definir as formas de acesso entre direto, habitual e disruptivo. Enquanto o primeiro estaria relacionado aos agentes oficiais do Estado, que estão presentes nas notícias de forma prioritária, o habitual acontece em reportagens investigativas e materiais que levantam temas que fogem aos interesses dos primeiros, e a disruptiva são as ações populares e de movimentos sociais que irrompem o cotidiano em manifestações e acontecimentos que geram incômodos à sociedade.

\footnotetext{
3 Decreto número 9.288 de 16 de fevereiro. Disponivel em: http://www.planalto.gov.br/ccivil_03/_ato2015-2018/2018/decreto/D9288. htm. Acesso em: 25 jul. 2020.

4 Decreto Legislativo número 10 do Congresso Nacional. Disponível em: https://www2.camara.leg.br/legin/fed/decleg/2018/decretolegislativo-10-20-fevereiro-2018-786181-publicacaooriginal-154895-pl.html. Acesso em: 25 jul. 2020.

5 Relatórios e dados do Observatório da Intervenção. Disponivel em: http://wwww.observatoriodaintervencao.com.br/dados/apresentacao-de-infograficos/. Acesso em: 25 jul. 2020.

6 Investimentos federais e gastos na Intervenção Federal no Rio de Janeiro. Disponivel em: http://www.observatoriodaintervencao.com. br/gastos-da-intervencao/. Acesso em: 25 jul. 2020.

7 Rio sob Intervenção. Datafolha/FBSPB. Disponível em: ttp://www.forumseguranca.org.br/wp-content/uploads/2018/04/FBSP_Rio_ sob_Intervencao_2018_infografico.pdf. Acesso em: 25 jul. 2020.
} 
O acesso desigual proposto por Molotch e Lester (1999) se torna ainda mais crescente ao verificarmos o poderio da profissionalização das fontes na atualidade com a formação de sólidas indústrias de relações públicas (SHOEMAKER; VOS, 2011). Chaparro (1994) chega a afirmar que vivemos uma "revolução das fontes" em que esses agentes buscam na sofisticação das relações com a imprensa, mecanismos para produzir e promover acontecimentos que geram conteúdos e interferem na pauta jornalistica. Sant'Anna (2009) avança na discussão com a proposta de mídias das fontes que exercem o papel de sensibilizar a pauta de jornais, emissoras de rádio e televisão e o próprio público que cultivam, indicando que, cada vez mais, organizações públicas ou privadas investem na comunicação direta com seus públicos de interesse e fornecem grande volume de informação para amparar a construção do noticiário.

Nesse sentido há uma diferença substancial a ser considerada na complexidade de relações estabelecidas no momento da seleção e do processo de gatekeeping realizado por diferentes funções no organograma das redações em radiojornalismo. De acordo com Shoemaker e Vos (2011, p. 14) o gatekeeping é um processo multidimensional permeado pela especificidade do meio e pelos niveis de análise individual, das rotinas em que os profissionais estão inseridos, no organizacional, das instituições e do sistema social. Segundo os autores são esses agentes que "determinam aquilo que se torna a realidade social de uma pessoa, sua forma particular de ver o mundo".

Na perspectiva de construção da realidade social em que o jornalismo se junta a outros âmbitos como a Igreja, a Escola e as próprias relações sociais (BERGER; LUCKMAN, 2004), as fontes são partes interessadas no processo de disputa dos sentidos sobre os acontecimentos. Pinto (2000) destaca que a definição conceitual do termo envolve pessoas, grupos, instituições sociais, além de vestígios, falas, documentos e outros dados que são construidos com objetivo de se tornarem notícias.

Como apontado anteriormente (KISCHINHEVSKY; CHAGAS, 2017, p. 113), as fontes populares podem ser definidas como "pessoas comuns, que se apresentam como vítimas de determinada situação - um crime, uma injustiça, uma política pública ineficiente - ou lançam mão de táticas de espetacularização para conseguir visibilidade e reivindicar melhorias no seu cotidiano". Majoritariamente nas pesquisas sobre jornalismo, a preferência dos profissionais se dá pelas fontes oficiais, ou seja, "ocupantes de cargos eletivos e funcionários do Executivo, do Legislativo, do Judiciário e do Ministério Público, em níveis federal, estadual e municipal". Autores como Hall et al. (1999), Lage (2001), Pinto (2000), Gans (1980), Schmitz (2011), Manning (2001) e Franklin (2011) evidenciam a preferência pelos setores estatais e institucionais na construção das notícias. Para Traquina (2005), isso decorre da hierarquia da credibilidade que colocaram na história as elites em diferentes niveis como habilitados a falar sobre os rumos da sociedade.

É preciso reconhecer, no entanto, que o mesmo cenário de crescimento das fontes profissionalizadas também é envolvido pelo crescente envolvimento do público com a construção das noticias jornalísticas (BRUNS, 2011). O conceito de gatewatching auxilia a compreender as dinâmicas dessa integração por meio da curadoria colaborativa como um recurso que teve ascensão de práticas e plataformas oriundas da cultura digital. Um desses espaços é o WhatsApp que chegou a ganhar uma função especifica na redação da BandNews (CHAGAS, 2018a), mas não se revelou como uma potencialidade na diversificação de experiências e pontos de vista, circunscrevendo as contribuições do cidadão comum aos temas de segurança e trânsito como uma forma de interação regulada (CHAGAS, 2018b; CARPENTIER, 2012). No caso da CBN, buscamos diferenciar o realizado em pesquisas anteriores situando as propostas conceituais de Carpentier (2012) no modelo Acesso, Interação e Participação (AIP) para as fontes populares na temática de segurança. Dessa forma é preciso entender as diferenças entre os conceitos de Acesso, Interação e Participação.

Ainda segundo Carpentier (2012), é preciso fugir da superficialidade proposta no conceito de conver- 
gência e aprofundar as referências políticas e sociais que diferenciam os mecanismos que proporcionam a presença do público nas mídias. O que salienta essa afirmação está presente no rádio, que desde suas primeiras transmissões, já utilizava a carta e depois o telefone como formas de comunicação entre o ouvinte e as redações. O que há para o autor é uma potencialização das plataformas que possibilitam o envio de diferentes mídias e relatos para os meios de comunicação. Porém, essas relações são supervalorizadas de uma forma que reduz a presença do público uma função de marketing para o envolvimento desse com a emissora.

Lopez (2010) complexifica essa relação e afirma que com o envio de informações substanciais dos ouvintes para o rádio torna este uma fonte na programação. Já Kischinhevsky (2016a), ao propor que o rádio na atualidade é expandido e vai além da plataforma hertziana identifica nas interações com os ouvintes algumas das estratégias de construção da notícia que ainda busca inserir na profissão parâmetros que conduzam a informações de qualidade.

Nesse sentido Carpentier (2012) propor o Modelo AIP e diferencia Participação, Interação e Acesso da seguinte forma: a) Participação vem do latim "particeps" como base da tomada de poder e influência nos processos de decisão, em tomar parte de algo. Nesse sentido o conceito vai além do simples envio de dados de um ouvinte para a redação e tem como elemento fundamental a distribuição de poderes em distintos campos, da política aos meios de comunicação, em niveis micro e macro. Essa mesma relação se fez presente em processos e localidades como fundamento das lutas de poder na sociedade e não necessariamente se baseia na troca de diferenças hierárquicas pela igualdade total; b) Interação se torna parte da construção de sentido expressa pela linguagem em relações sociocomunicativas e de troca por meio de experiências vivas, reais ou então intersubjetivas; c) Acesso, por sua vez, é a garantia da presença de vozes ou agentes no discurso dos meios de comunicação com reivindicações, propostas de solução para os problemas sociais ou meramente manifestações sem um interesse específico ex- presso em suas mensagens (CARPENTIER, 2012). Segundo o autor, os dois casos não possuem uma dimensão de poder, mas são condições que levam à possibilidade de participação.

Em resumo, o modelo AIP de Carpentier (2007) apresenta as seguintes proposições: I) O acesso condiz à presença desses agentes nos conteúdos produzidos pelo radiojornalismo como fontes ou até a forma com que são abordados os diferentes setores sociais; II) A interação advoga o ato de estar coproduzindo, enviando dados, ou incrementando as notícias a partir de relatos pessoalmente ou via crowndsourcing; III) A participação, como um nivel mais aprofundado dessa relação, é decisão conjunta sobre os acontecimentos a serem abordados ou quais conteúdos merecem entrar na pauta.

A partir disso, considerar que a presença de mensagens via WhatsApp ou outros aplicativos que estabelecem a relação com o ouvinte configuram uma participação se torna equivocado. $O$ pesquisador israelense Zvi Reich (2011) questiona esse processo a partir de fatores que dificultam a presença de cidadãos comuns como fontes ou potencialmente noticiosos. Segundo o autor, por mais que tenhamos um acesso às tecnologias de comunicação que favorecem a busca por novas vozes, trocas de mensagens instantâneas e outras tarefas possiveis, o advento de todos esses avanços não foram suficientes para reduzir a preferência tradicional dos jornalistas pelos setores oficiais ou profissionalizados. Para Reich (2011, p. 2416), o tratamento com indiferença e hostilidade, em muitos casos, decorre da falta de confiança a partir de três conjuntos de fatores:

a) Circunstancial: a busca pela autoridade profissional e na defesa de que "cidadãos comuns não podem se tornar jornalistas substanciais" recebendo voz em circunstâncias raras em acontecimentos não programados, entrevistas ilustrativas, assuntos domésticos ou minorias e não em assuntos políticos ou econômicos;

b) Logístico: sem incentivo estrutural para confiar em cidadãos comuns, a busca por esse tipo de vozes demanda de energia e gastos, da saída da redação e recursos físicos, simbólicos, conhecimento comu- 
nicativo, além de uma regularidade que demandam os jornalistas;

c) Avaliativo: cidadãos comuns são considerados agentes com pouco poder informativo ou status de autoridade e muitas vezes distante do mundo cognitivo dos jornalistas, causando até mesmo dúvidas sobre o valor informativo que podem fornecer.

Essas condições envolvem o trabalho e a compreensão dos jornalistas na pesquisa de Reich (2011, p. 2423) nas respostas das entrevistas realizadas pelo pesquisador. Os resultados levaram a três variáveis que tentam explicar como os fatores influenciam no silenciamento desses agentes: I) Variável circunstancial: "a dependência de cidadãos comuns limita-se a circunstâncias ritualizadas especificas e pouco frequentes" e se fazem presentes em eventos não programados, durante a etapa de coleta ou quando necessita testemunhar algo, fora de assuntos complexos ligados à política ou economia; II) Variável logística: o contato com fontes populares ou cidadão comum se dá no local dos acontecimentos fugindo da ritualidade das fontes oficiais ou institucionais realizadas por telefone e regularmente; III) Variável avaliativa: os jornalistas consideram as contribuições de cidadãos comuns como menos informativas ou sem a importância e interesse que outras fontes.

É importante, nesse sentido, questionar a ideia de credibilidade ou o que os jornalistas consideram credivel quando o assunto são as fontes. Reich (2011) em outra pesquisa, argumenta que a atenção ainda é limitada quando liga-se o tema com as vozes selecionadas pelos jornalistas. $O$ autor destaca que a "familiaridade" e a "credibilidade" estão associadas ao modelo de seleção desempenhado pela comunidade profissional, o que reforça uma hierarquia a partir da regularidade do contato e do subsídio de informações. Em uma pesquisa com 80 repórteres israelenses com idade média de 36 anos e 13 anos de experiência no campo, Reich (2011, p. 33) identificou aspectos estruturais e práticos em que o ganho de "credibilidade é utilizado contra a perda de tempo e outros recursos [...] e que as hierarquias são mais rígidas, no qual fontes experientes tem pouca vantagem sobre organizações assessoradas profissionalmente".

Ao final, é possivel identificar na pesquisa três estratégias utilizadas para encontrar a confiabilidade na seleção das fontes dentro dos valores da comunidade defendido por Reich (2015, p. 31): a) relação estratégica e acoplamento entre fontes confiáveis com intensidade de trocas de subsídios que podem oferecer ao longo do tempo "acesso superior a fontes ricas em recursos que estão mais bem posicionadas"; b) a redução de fontes "problemáticas" com as verificações cruzadas que ocorrem ainda na fase de coleta de notícias "em proporção inversa à credibilidade da fonte percebida"; e c) destinação de mais espaço para quem consideram mais confiáveis que resulta na "proeminência e dominância para com os mais críveis". Mesmo apontando as estratégias a partir das entrevistas com os jornalistas, Reich (2011) ainda questiona aspectos centrais e problemáticos na relação com as fontes quando a) os profissionais julgam a credibilidade de agentes com pouco acesso às notícias; b) a destinação de espaços consideráveis para versões menos confiáveis, mas de sujeitos proeminentes; e c) a verificação de apenas um terço de itens noticiosos que envolviam apenas fontes tidas com alto grau de credibilidade.

É importante ressaltar que identificamos aqui o cidadão ou a cidadã comum como fontes populares selecionadas pelos(as) jornalistas na temática de segurança pública. Entendemos essa fonte a partir da ideia de marcos interpretativos de Porto (2003) olhando o cidadão comum como o cidadão interpretante inserido no espaço de sua comunidade. Como destaca Spivak (2010), o fato de a ausência da voz estar presente em espaços como o jornalismo não se dá pelo local, profissão ou conhecimento teórico-informativo sobre o mundo, mas sim pela violência do colonialismo presente nesses ambientes.

Dessa forma, entendemos o cidadão comum como fonte, subalterno e capaz de articular o conhecimento sobre suas realidades e que necessita de uma análise pela lógica da sociologia das ausências, da cidadania para os "não cida- 
dãos" (SANTOS, 2002) e da marginalidade social (QUIJANO, 1978) que são colocados quando buscamos entender as formas de seleção dos jornalistas. Não há a proposição de que todos e todas devem ser selecionados, que todas as vozes precisam estar presentes na programação das emissoras. A questão é sobre a racionalidade que envolve a seleção prioritária sobre fontes oficiais (como os politicos e instituições) em detrimento da possibilidade de escuta e potencialização das fontes populares (moradores, atingidos) em casos de segurança pública.

Por fim, De Keyser, Raeymaeckers e Paulussen (2011) ao questionarem a hierarquia das fontes e o acesso como ideal habermasiano na esfera pública, identificam que os jornalistas políticos e econômicos fazem parte do primeiro grupo que tende a preferir membros da elite para suas notícias. Mesmo ONGs reconhecidas internacionalmente, juntamente com os cidadãos comuns ficam em último lugar de suas preferências. No caso de jornalistas que atuam exclusivamente para portais de internet, a hipótese de que a preferência por contatos fáceis de usar e o público foram refutadas, pois mais uma vez o governo, colegas jornalistas, pesquisadores e empresários figuram como mais importantes na seleção. Nesse quesito, o dado interessante foi de que quem distribui mais releases, tem mais chances de ser selecionado.

Este se torna um cenário de privilégio às fontes primárias como identificou Hall et al. (1999) na pesquisa que identifica a seleção prioritária por fontes policiais nos casos dos assaltos rotineiros. O agenciamento primário foi criticado por Manning (2001) como algo não fechado nas redações e que pode ser subvertido ao longo do trabalho pela heterogeneidade de interesses existentes. Por outro lado, o próprio autor reconhece que o momento vivenciado por jornalistas do mundo todo é de dependência, como também identificam Franklin (2011) e O'Neil e O'Connor (2008) e de passividade (ELÍAS, 2003) frente aos materiais de setores profissionalizados de fontes oficializadas. Como as vozes populares participam dessa disputa no cenário do radiojornalismo? Como a relação entre os mecanismos de interação pro- porcionados pelas tecnologias de comunicação entre fontes populares subsidia o jornalismo no rádio expandido atual?

\section{As fontes populares no debate sobre segurança pública na CBN Rio}

Com o objetivo de analisar como o cidadão comum é selecionado como uma fonte na cobertura sobre segurança pública no Rio de Janeiro pela CBN, buscamos três vias de coleta de dados durante o período de uma semana na emissora. Durante os dias 13 a 17 de agosto de 2018, segunda a sexta-feira, realizamos uma análise de conteúdo dos programas locais que vão ao ar das 9 h3o às $12 \mathrm{~h}$ ao lado de uma observação sistemática no mesmo periodo e entrevistas semiestruturadas com os jornalistas responsáveis pela seleção das fontes e construção das notícias. A proposta multimetodológica considera as dinâmicas do rádio expandido e a proposta em considerar

elementos parassonoros, exigindo do pesqui-
sador atenção não apenas ao conteúdo veicu-
lado em ondas hertzianas, mas à sua replicação
em sites, considerando-se o que caracteriza
sua publicação em outras plataformas e toda
a comunicação que se engendra a partir daí
(KISCHINHEVSKY, 2016b, p. 291).

No primeiro caso, a análise de conteúdo tem como base as frequências empíricas entre os tipos que serão unidos à discussão teórica e contextual para então gerar argumentos em conjunto com aspectos qualitativos já apresentados pelas entrevistas e observações (BARDIN, 1977). Essa segmentação permite olhar para formas de pluralidade e diversidade de vozes entre os tipos de fontes (HERSCOVITZ, 2007). Dessa forma, as categorias de análise são os a) tipos de fontes selecionada; b) formas de interação/participação/acesso no caso das fontes populares via WhatsApp; c) fontes selecionadas na temática de segurança.

As entrevistas semiestruturadas, nas quais insere-se no momento da coleta de dados objetivos e subjetivos, como forma tradicional nas pesquisas das ciências sociais (PATHERSON, 2008; GIL, 2008; TRIVIÑOS, 1987), procuraram explorar as opiniões dos jornalistas nas redações 
das emissoras a partir diferentes representações sobre o cotidiano da cobertura com o foco na seleção das fontes (GASKEL, 2002). A variável de escolha dos entrevistados passou pela função desempenhada na redação em torno da seleção das fontes com os seguintes participantes: gerente de jornalismo, Thiago Barbosa; a âncora Bianca Santos; o produtor Ricardo Porto; e a repórter da central de apuração Rafaela Cascardo.

Se a atividade jornalística é um papel socialmente legitimado para "gerar construções da realidade publicamente relevantes" (ALSINA, 2009, p. 46), as ações dos jornalistas, por sua vez, também carregam a relevância nesse processo. Dessa forma, as técnicas da etnografia auxiliam a estudar as competências realizadas e as subjetividades desses agentes nas redações. Nesse sentido, a observação sistemática permite uma descrição precisa dos fenômenos observados a partir de aspectos já escolhidos como significativos para a pesquisa (GIL, 2008). O plano de trabalho inicia com a observação do contexto e a descrição dos locais e das pessoas observadas com detalhes de suas funções na redação para as atitudes desempenhadas na seleção das fontes, assim como o comportamento diante do pesquisador no conjunto das produções. O plano foi delimitado para os seguintes tópicos: a) utilização das novas tecnologias na seleção de fontes; b) tratamento dado aos diferentes tipos de fontes; c) fontes profissionalizadas $x$ não profissionalizadas e interferência na construção da notícia.

Para entendermos a importância que o rádio e suas modalidades de difusão possuem na atualidade recorremos a alguns dados do Kantar Ibope Media. Na pesquisa realizada pelo Ibope Media 2018,8 86\% da população entrevistada em 13 regiões metropolitanas têm o rádio como meio de comunicação no seu cotidiano. Desses, três a cada cinco ouvem todos os dias e a média de escuta de 4 horas e 40 minutos por dia. $O$ tempo médio diário é de 2h21min e no caso do jornalismo, que é nosso foco, 83\% preferem o rádio pela facilidade de entendimento, $78 \%$ porque o meio oferece notícias que são confiáveis e $74 \%$ escolhem programas noticiosos nessa mídia por oferecer "comentários e análises em profundidade".

Nesse cenário está a Central Brasileira de Notícias (CBN), que iniciou as transmissões em 1991 e integra o Sistema Globo de Rádio com quatro emissoras próprias em São Paulo, Rio de Janeiro, Brasilia e Belo Horizonte, além de 27 filiadas presentes em 20 Estados mais o Distrito Federal. No Media Kit ${ }^{9}$ disponivel para anunciantes do site do SGR, a empresa afirma ter um potencial de atingir 87 milhões de brasileiros pela formação em rede e alcançar mensalmente 6 milhões de pessoas. Entre outubro a setembro de 2017, o documento expõe um número de 2,4 milhões de usuários únicos do aplicativo e do site da emissora, além de 3.7 milhões de downloads únicos de podcasts por mês. Os ouvintes são maioria homem (64\%), das classes AB (59\%) seguidas de C com 36\% e DE com 5\%; e com as faixas etárias de 25 a 49 anos (41\%), 50 a 59 (23\%) e 60 anos ou mais com 33\%.

O número de fontes utilizado pela CBN Rio durante o periodo de uma semana e a distribuição entre a tipologia selecionada para a construção das notícias reflete o pensamento estruturado nas entrevistas com os integrantes da redação e a própria observação sistemática ao longo da semana. As afirmações relacionadas com a confiança nos setores oficiais e profissionalizados, bem como a dependência e até mesmo a passividade diante dos materiais de órgãos são verificados na análise de conteúdo como parte dos dados apresentados sobre as vozes utilizadas em reportagens, notas, boletins, entradas ao vivo e comentários de analistas.

Como demonstrado no Gráfico 1, a segurança (72,7\% dos casos) é a principal temática em que os ouvintes são acionados com envios de relatos e busca de dados sobre tiroteios, fechamento de vias e operações, em sua maioria como resposta a pedidos dos âncoras durante a apuração em conjunta com órgãos oficiais. Também nesse

\footnotetext{
8 Book de rádio da Kantar lbope Media 2018. Disponivel em: http://br.kantaribopemedia.com/downloads/Bookderadio_2018.pdf?utm source=akna\&utm_medium=email\&utm_campaign=Errata+\%7C+Book+de+R\%26aacute\%3Bdio+2018. Acesso em: 23 maio 2020 .

Media Kit "Somos CBN". Disponível em: https://anunciesgr.globo.com/cbn/documentos/midia-kit.pdf. Acesso em: 23 maio 2020.
} 
sentido, impossibilitada de estar em todos os lugares e acompanhar somente pela Central de Operações da Prefeitura do Rio de Janeiro, os ouvintes são partes da cobertura de trânsito em $18,2 \%$ dos casos de interação. Politica e Saúde com 4.5\% tiveram apenas dois casos em que os ouvintes participam de questionamentos realizados, no primeiro caso sobre o patrimônio dos candidatos quando da análise dos planos de governos pelos especialistas da casa; e no segundo, de reclamações realizadas junto ao defensor público da União, entrevistados sobre o caso do Hospital Federal de Bonsucesso.

Gráfico 1 - Fontes populares por temáticas CBN Rio

Gráfico 1: Fontes populares por temáticas C'BN Rio

Fonte: autoria própria

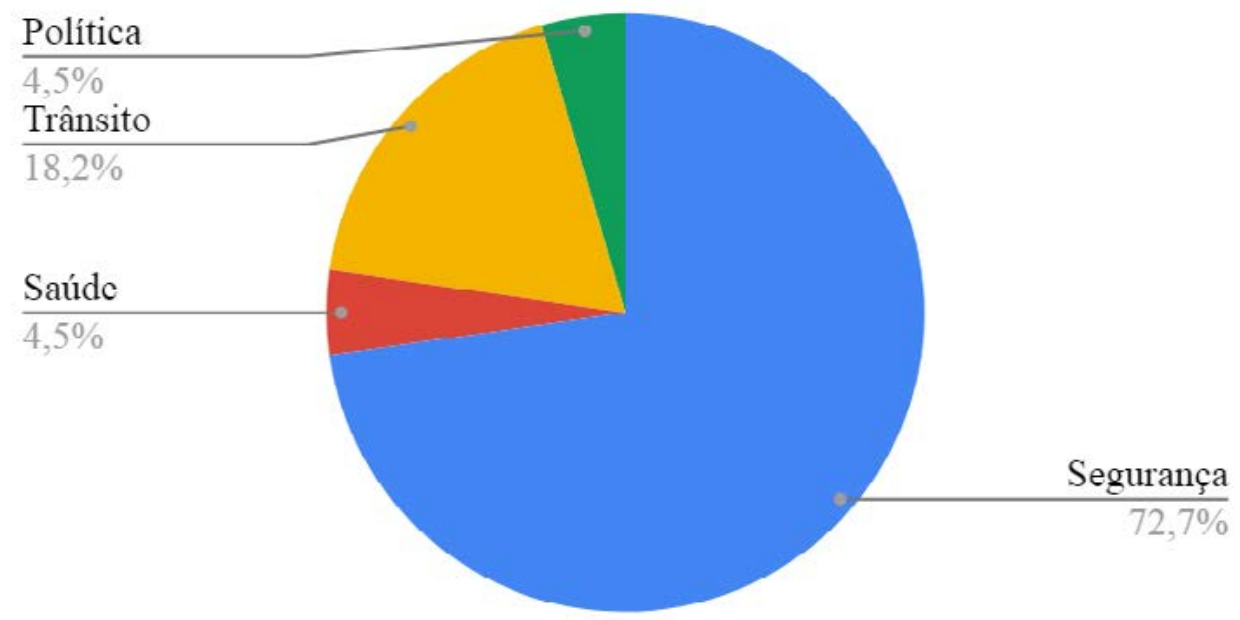

Fonte: Elaborado pelo autor (2020).

Ao longo dessas temáticas é possível verificar a presença em $51,6 \%$ de fontes oficiais de um total de 128 vozes presentes durante a semana. $O$ detalhe é que a confiança demonstrada na busca pela apuração em conjunto com esses setores é analisada pela forma de menção, todas diretas, citando o órgão ou responsável pela informação que foi repassada, sendo que a metade delas, sem a presença de sonoras ou vozes. Mesmo que representem menos da metade das fontes oficiais, os cidadãos comuns aparecem na CBN por meio de interações reacionais ampliadas, ou seja, respondendo a solicitações da emissora em quatro temas centrais.

As fontes populares ficaram com $18,8 \%$, especialistas têm $10,2 \%$, testemunhais com $7,8 \%$, empresariais (5.5\%), institucionais (3.9\%) e notáveis (2,3\%). No caso das fontes populares é necessário aprofundar essa relação por duas frentes: foram apenas dois casos em que cidadãos comuns foram buscados pelos jornalistas no palco de acontecimentos na reportagem realizada sobre os preços do álcool em comparação com outros combustiveis no Rio de Janeiro. O restante foi estabelecido a partir do contato via WhatsApp, no estúdio da emissora, na área de segurança. Mais uma vez, também segundo o argumento de Reich (2011) e Manning (2011) não há uma exploração igualitária no sentido temático das vozes populares e não alinhadas a setores oficiais.

É possivel confirmar nesse caso a proposição de Reich (2015) sobre a relação estratégica desempenhada com fontes ditas confiáveis, no caso das oficiais e a redução de fontes tidas como "problemáticas". Nesse caso, sem a credibilidade de outros setores, mesmo com a seleção das vozes do cidadão comum, elas ainda passam pela confirmação dos dados junto a órgãos oficiais. Com 
isso o resultado é a garantia de um espaço maior aos órgãos confiáveis socialmente. O produtor Ricardo Porto (informação verbal, 2018) ${ }^{10}$ reconhece que ainda não existe uma mudança completa no caso da emissora em relação à interação com os ouvintes, mas sim um "espaço maior" para fontes não oficiais. Isso, para o produtor também é resultado das mudanças ocorridas no formato de seleção das fontes. Essa mudança, salienta, é gerada por conta de novas formas de contato, sem a necessidade de presença na rua em alguns casos. Quando começou na emissora, as ligações via telefone eram comuns para o relato de tiroteios, tendo a necessidade de contactar a PM para a confirmação e posteriormente levar ao ar: "Eu entendo esse cuidado porque é uma busca pela correção, a gente não necessariamente vai ser o primeiro a dar a notícia, mas a gente vai dar a notícia correta" (informação verbal, 2018). ${ }^{11}$

Isso também fica evidente na observação sistemática em que a repórter Rafaela Cascardo responsável pela central de apuração, atua no formato do jornalista sentado (NEVEU, 2006), realizando o contato com fontes oficiais, fazendo uma curadoria de materiais oriundos de diferentes setores via telefone e aplicativos de mensagens instantâneas. O contato é realizado por meio de aplicativos para o levantamento e apuração de pautas com fontes oficiais e assessorias de imprensa. Esses aparatos, o Facebook, telefone, WhatsApp e uma agenda de contatos no sistema interno utilizado pela CBN são os principais dispositivos para a interação com os agentes externos à redação.

Os sites de monitoramento da cidade, aplicativos de crowdsourcing e o próprio contato com assessorias de imprensa por meio do WhatsApp são partes desse processo que evidencia as estratégias para a seleção de vozes. Como foi observado na redação, a linha editorial da CBN é explicitada no trabalho dos repórteres, produtores e âncoras que garantem um acesso direto a fontes oficiais como as polícias Militar e Civil na cobertura de segurança pública. Exemplo disso acontece na quarta-feira, com a Polícia Militar que se torna a principal voz no caso do professor assassinado na frente da família próximo a um condomínio na Barra da Tijuca. Os dados são levantados tanto pela produção, como pela repórter Rafaela Cascardo diretamente pela assessoria da PM por meio do WhatsApp e por telefone.

Na interação, Cascardo, que mantém o contato diário com os ouvintes afirma que a entrada das informações como sonora ou como pauta na programação da emissora demanda de confiabilidade e subsídio na construção das notícias. Segundo ela, os casos de problemas pessoais ou situações especificas não são relevantes no contexto geral que necessitam as notícias. Os valores notícias seriam acionados para pensar o que é importante para a sociedade ou não na seleção do gatekeeper: "Meu filtro é verificar o que vai impactar a população ou que está impactando especificamente a vida dele" (CASCARDO, informação verbal). ${ }^{12}$

A correção como sinônimo de credibilidade é parte das considerações que os jornalistas relacionam na construção de uma hierarquia das vozes com o poder de falar sobre os acontecimentos (TRAQUINA, 2005; MANNING, 2011). Segundo os entrevistados, o formato de trabalho das emissoras também privilegia a oficialidade. $\mathrm{O}$ gerente Thiago Barbosa argumenta que a preferência pelas fontes oficiais é tida como forma de garantir ao ouvinte um material checado e com a confirmação de órgãos que detenham o poder de garantir a "veracidade" dos fatos:

Têm alguns institutos que acabam sendo de maior credibilidade a gente já usa e já dá o crédito, como informações do IBGE da Fundação Oswaldo Cruz que são instituições que a gente confia totalmente, porque até hoje eles nunca erraram ou mentiram de alguma maneira que nos coloque em alguma forma em descrédito (BARBOSA, informação verbal). ${ }^{13}$

Dessa forma, o gerente de jornalismo (BARBOSA, informação verbal) elenca que a lista de

\footnotetext{
Entrevista realizada no dia 17 de agosto de 2018, no Rio de Janeiro, RJ, Brasil.

Entrevista realizada no dia 17 de agosto de 2018, no Rio de Janeiro, RJ, Brasil.

Entrevista de Cascardo concedida ao autor em 17 de agosto de 2018, na cidade do Rio de Janeiro, RJ, Brasil.

Entrevista de Thiago Barbosa concedida ao autor em 2018, na cidade do Rio de Janeiro, RJ, Brasil.
} 
fontes ainda precisa contemplar informações importantes, "falar bem, debater bem, discutir bem" como critérios para decidir quem irá emitir suas opiniões sobre determinado assunto, reconhecendo a possibilidade de levar ao ar primeiro para depois apurar no caso de vozes oficiais. 0 relato reforça caracteristicas de imediaticidade do rádio e de construção contínua ao longo da programação e não fechada em si mesmo, no qual as fontes oficiais exercem o papel de ditar os acontecimentos e o cruzamento necessário em fontes tidas como menos crediveis.

São esses departamentos e assessorias de imprensa que ditam o que é importante no tratamento de dados sobre a intervenção federal no Rio de Janeiro, com o cruzamento de aplicativos de crowdsourcing, como é o caso do Onde Tem Tiro (OTT). Dessa forma, os dados coletados na programação somente reforçam o encaixe das vozes populares na temática de segurança na qual a identificação é suprimida na maioria das vezes, sendo citada de forma indireta em 79,2\% das menções. Por outro lado, a utilização da voz também é maioria em 70,8\% contra 29,2\% de casos em que a somente a informação é citada.

No caso da seleção de diferentes fontes e a definição de quem fala e quem somente indica possiveis pautas ou interfere na programação sem aparecer, a âncora Bianca Santos (informação verbal) ${ }^{14}$ argumenta que depende da relevância da notícia e do acesso à fonte: "Se ela falar 'olha essa informação que eu estou te passando é em off, não quero colocar a minha voz', isso acontece também com ouvintes que moram, por exemplo, em áreas de risco, ele tem medo de represália, de se tornar alvo" (BARBOSA, informação verbal). ${ }^{15}$

O contato via WhatsApp é realizado durante toda a apresentação do CBN Rio e, mesmo na ancoragem, Bianca Santos mantém a busca por informações via aplicativo e o contato com as fontes ao longo do programa:

Em outros casos, se ele optar por falar, ai é muito relevante porque no rádio a voz é fun- damental e isso dá um corpo à matéria, torna a matéria ainda mais importante mais especial, então na maioria dos casos a gente prioriza a sonora, se ele topar falar, se ele quiser ir pro ar, a gente vai dar esse espaço pra sonora (BIANCA SANTOS, informação verbal). ${ }^{16}$

A fonte oficial da quinta-feira que mais repercute durante a apresentação do CBN Rio é a entrevista com o comandante da intervenção federal no Rio de Janeiro, Richard Nunes, pré-agendada também por meio da assessoria de imprensa. Entre as principais fontes, estiveram o Centro de Operação da Prefeitura do Rio de Janeiro sobre a situação viária, de trânsito e de operações realizadas nas estradas. Os repórteres seguiram a agenda oficial com a coletiva sobre o balanço dos seis meses da intervenção federal com uma reportagem que ouviu testemunhas de tiroteios no Rio de Janeiro e uma coletiva com o Observatório da Intervenção.

O cidadão comum esteve presente em temas recorrentes, como casos de violência na Zona Oeste, Niterói e Comunidade do Rola, em um primeiro momento sobre os tiroteios e falta de circulação de ônibus e depois para situar os jornalistas sobre a presença de policiais e forças armadas em alguns dos locais. Além disso, há dois comunicados, um sobre o roubo de grades no elevado das Bandeiras, que não continua a ser debatido pela programação, e o roubo de carga na Avenida Brasil, que gera uma reportagem com dados de outras fontes. Os relatos ainda são utilizados sobre problemas no atendimento de hospitais por conta da violência em São Gonçalo e Niterói e a situação da Avenida Niemayer após tiroteios. Nesse sentido, há uma prática de construção das notícias por meio do gatewatching (BRUNS, 2011), mas a fonte popular não aprofunda a relação existente entre a ação e a busca por um desfecho ou política pública para suas comunidades, restringindo esse espaço ao relato humano.

Diferentemente das populares, os sociólogos especializados em segurança pública que ana-

14 Entrevista de Bianca Santos concedida ao autor em 2018, na cidade do Rio de Janeiro, RJ, Brasil.

15 Entrevista de Thiago Barbosa concedida ao autor em 2018, na cidade do Rio de Janeiro, RJ, Brasil.

Entrevista de Bianca Santos concedida ao autor em 2018, na cidade do Rio de Janeiro, RJ, Brasil. 
lisaram os seis meses de intervenção federal, Paulo Storani e Roberto Kant de Lima ofereceram discussões durante mais de 25 minutos sobre alternativas para o descaso da área na cidade. 0 mesmo ocorre de forma prioritária com as oficiais. As Polícias Militar e Civil e o Ministério Público foram agentes preponderantes e únicos nas reportagens e notas sobre as operações contra o jogo do bicho (que tiveram informações relatadas com base na transmissão da TV Globo). Outras operações que tiveram os órgãos militares como mais ouvidos foram os casos do Complexo do Lins com tiroteios; em São Gonçalo, contra esquemas de exploração sexual infantil; e ações no Morro da Mineira e Catumbi inclusive com a morte de uma mulher por bala perdida.

Os tiroteios na Comunidade do Rola, que resultaram na interrupção da circulação do BRT na região; no Morro Santa Marta, com ataques a policiais; e confrontos na Avenida Niemayer; além do assassinato do cantor MC G3, em Duque de Caxias, estiveram presentes nas respostas solicitadas à assessoria da PM no Rio de Janeiro. Já a Polícia Civil foi a principal fonte de reportagens com os casos do latrocínio contra um professor, o assassinato da corretora Karina Garofalo pelo ex-marido na Barra da Tijuca e o caso de uma vítima de bala perdida dentro de um hospital próximo ao morro Santa Marta.

Também outras fontes oficiais são ouvidas sobre segurança pelo CBN Rio: a Polícia Rodoviária Federal, sobre um assalto a um depósito em Nova Iguaçu, o caso do decreto do Interventor Federal, General Valter Braga Neto, que extinguiu a delegacia do Complexo do Alemão, a ausência de resposta da intervenção sobre a visita da Anistia Internacional que buscava respostas sobre as investigações do caso Marielle Franco, o secretário de segurança do Estado, general Richard Nunes e o Ministério Público com denúncias realizadas contra o médico Denis Furtado, conhecido como "doutor bumbum", por homicidio doloso.

A disparidade na consideração sobre as fontes pode ser verificada também nos argumentos de Bianca Santos (2018) ao elencar a necessidade de cuidados de informações que chegam via
WhatsApp quando relacionadas a cidadãos comuns. Não há o reconhecimento de que pode haver erros em falas ou comunicados por parte de fontes oficiais, oficiosas ou institucionais, como já destacou Chaparro (1994). No caso de mortes, feridos ou informações impactantes a determinadas comunidades, isso se acentua pela importância da correção na transmissão dos acontecimentos.

Por fim, há que se destacar nesse sentido a construção das notícias ao longo da produção do programa em um formato espiralado como característica do modelo de construção informativa no rádio All News como proposta na Figura 1. O exemplo está na construção da notícia sobre o caso do assassinato da corretora de imóveis Karina Garofalo. É possivel encaixar na Zona Alta 1, a informação de alerta sobre o assassinato de uma mulher na Barra da Tijuca, com fontes oficiais como a Polícia Civil e Polícia Militar, ainda no dia 15 de agosto. A Zona Baixa 1 é seguida com a análise de especialistas sobre os problemas decorrentes da violência e a suspeita de execução. No dia seguinte, a Zona Alta 2 novamente possui informações policiais sobre o depoimento do filho da mulher alegando que o pai seria o responsável pela execução e o primo teria sido contratado para fazer o serviço.

Na continuidade da informação, a Zona Baixa 2 possui comentários tanto da âncora, como do setor de apuração com casos de feminicidio no Brasil com especialistas que seguem ouvidos na emissora sobre o assunto. A Zona Alta 3, por fim, tem o desfecho da situação, no dia 16 de agosto, com a elucidação do crime e o planejamento do ex-marido. E por fim, a Zona Baixa 3, a entrada do assunto em uma entrevista com especialistas em segurança pública, na sexta-feira, 17 de agosto. 0 caso trágico de feminicídio é um dos exemplos que reforçam a ideia de uma estrutura de notícia espiralada e construida ao longo da programação do CBN Rio, sem um compromisso estático e carregado de características radiofônicas como a repetição, redundância, imediatismo e a alternância de vozes. Isso perpassa outras notícias e é apenas um exemplo de como o dia a dia de produção reflete na composição das notícias no radiojornalismo. 
Figura 1 - Espiral Radiofônica

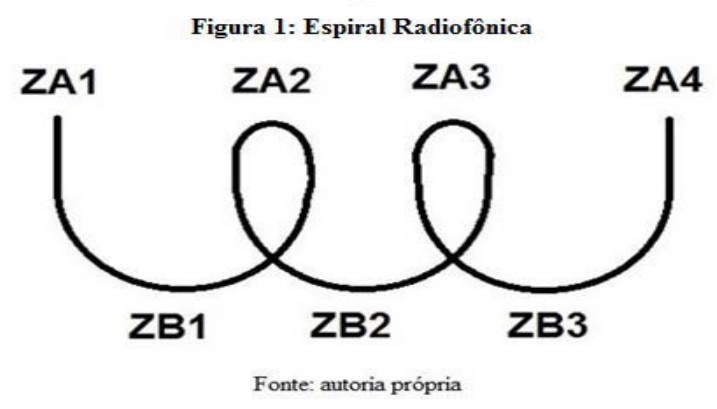

Fonte: Figura elaborada pelo autor (2020).

Por fim, o modelo de interação com os ouvintes, realizada com o controle da emissora por parte de jornalistas que antes de levar ao ar, verificam em conjunto com outras fontes e somente confirmam a informação após a resposta de órgãos oficiais, revela um acesso e confiança limitada nos cidadãos comuns (CARPENTIER, 2007; MOLOTCH; LESTER, 1999; REICH, 2011). A limitação é parte dos valores compartilhados pela comunidade interpretativa com relação às fontes, mas também impede a possibilidade de participação no pleno conceito de fazer parte da construção do noticiário e decidir sobre o andamento das pautas. Isso, de alguma forma é mais presente na entrada direta de informações oriundas de setores profissionalizados como as assessorias de órgãos oficiais ou a rede de fontes proporcionada pelo contato com especialistas, instituições e empresas que ditam os acontecimentos e possuem o acesso direto no cotidiano. Exemplo disso é de que nas 66 vezes em que uma fonte oficial aparece, em 55 essas vozes são acionadas como a principal e única fonte da notícia sem uma discussão com outros pontos de vista. Ou seja, o agenciamento primário é prática orgânica do meio e parte do processo de seleção das fontes.

A partir da observação, é possivel realizar uma sistematização de fontes que não possuem um aprofundamento na apuração ou que entram de forma direta na programação de acordo com o interesse dos jornalistas. As fontes oficiais e institucionais, desde que alinhadas a setores governamentais ou políticos têm suas falas consideradas prioritárias na cobertura. Nesses casos, o acesso é direto durante toda a cobertura local da emissora na apresentação do programa. O cidadão comum ainda é tido como uma fonte de baixa confiança, sujeitos subalternos silenciados quando a proposta é discutir ou aprofundar a temática na ótica de uma política pública. Restringido a falar sobre os relatos humanos, casos de tiroteios e os problemas que vive, compete a essa parcela aceitar a lógica que propõe aqueles que não vivem nas comunidades e favelas, como as fontes oficiais, a PM, o Exército, os especialistas e o mundo político.

\section{Considerações finais}

É possivel a partir disso considerar que como aponta Carpentier, (2007) no modelo AIP, há uma interação regulada que leva ao acesso, mas sem a possibilidade de participação e construção do noticiário pelas fontes populares. O gatewatching acontece, mas de forma a construir informações de interesse da emissora em conjunto com a seleção do gatekeeping na relação desempenhada a partir das fontes oficiais. Em apenas um caso, no roubo de uma carga na Avenida Brasil, o alerta de um ouvinte se torna uma pauta a ser apurada pela equipe de redação junto a outros órgãos, exigindo uma resposta por parte de setores oficiais com o papel secundário (HALL et al., 1999). A fuga do modelo de agenciamento primário é verificada nesse momento como também argumentou Manning (2011), mesmo que em uma proporção menor que o restante da cobertura da emissora.

A presença do outro, a alteridade e a busca do diverso pelas experiências dos pobres nas grandes e pequenas cidades ainda não repercutem com toda ressonância necessária que expresse as riquezas culturais que possuem (SANTOS, 2006). Não há, nesse sentido, uma abertura que busque relevar os argumentos oriundos das fontes populares, mesmo que estas exerçam o papel de entrar em contato com a redação da emissora. O próprio relato da repórter da central de apuração já evidenciava que questões pessoais que não afetam o conjunto não são consideradas, o que resulta em um controle direto sobre o material enviado de acordo com os interesses e demandas seguidas também por fontes oficiais. Nesse sentido, a 
própria lógica de participação, interação e acesso (CARPENTIER, 2012; MOLOTCH; LESTER, 1999) é impactada diretamente, já que há uma limitação no fator de acessibilidade que poderia levar a disputas de sentido sobre os acontecimentos.

A estrutura de trabalho característica de uma emissora presente em um dos principais centros econômico-políticos do país é prejudicada pela falta de condições de cobrir a cidade ou pontos dela. Nesse caso, a ausência dos cidadãos comuns está inserida em um ambiente que favorece a entrada de vozes oficializadas pelos canais de rotina já estabelecidos e pelos valores compartilhados pelos profissionais da emissora. A reflexão sobre a entrada dessas vozes na cobertura não necessariamente isenta da necessidade de apuração ou verificação em conjunto com outras fontes. A necessidade da igualdade e do equilibrio se mantém, independente das vozes acionadas e selecionadas.

A estruturação desse modelo de trabalho, realizada ao longo de vários anos e já demonstrada em outras pesquisas (LOPEZ, 2009) também é permeada pelo baixo número de jornalistas que podem atuar na cobertura cotidiana da emissora. O resultado é a concentração da tarefa de apurar uma série de acontecimentos da cidade em um repórter que se torna dependente das assessorias de imprensa e da resposta dos órgãos oficiais.

Os valores compartilhados por meio das entrevistas revelam que a desconfiança em relação ao cidadão comum é uma característica que leva à passividade frente aos discursos oficializados. A preferência por um em detrimento do outro inviabiliza o equilibrio necessário na cobertura que revela uma disputa de sentido desigual em que setores como as policias, exército e outras forças militares expõem suas lógicas em evidência, enquanto as violações ficam em segundo plano ao não ouvir os cidadãos em sua plenitude. É possivel apontar, como também destacam Spivak (2010) e Santos (2002) para a urgência em pensar o jornalismo a partir dos silenciamentos, das vozes que não se fazem presentes nesse cotidiano. Por outro lado, também revelam indícios que ainda devem ser aprofundados de uma racionalidade colonizadora na seleção das fontes pela prioridade às fontes oficiais como estratégia e valor compartilhado na comunidade interpretativa.

Como aponta Reich (2011), há uma seleção apenas circunstancial nos relatos humanos que reforçam a ideia da presença das fontes populares em casos de tiroteios, assassinatos, roubos e outros acontecimentos. Por outro lado, o aprofundamento dessas discussões que destina aos cidadãos o papel de debater os desdobramentos e políticas públicas, as variáveis logísticas e avaliativas impedem a presença destes na cobertura. A observação sistemática demonstrou que a preferência pelas fontes oficiais também é resultado do formato de trabalho e da saida de profissionais para acompanhar eventos rotineiros desses setores como coletivas, operações pelo viés da PM, entre outras atividades. Isso resulta na avaliação de que os cidadãos comuns ainda são considerados agentes com pouco poder informativo (REICH, 2011) e demandam do cruzamento das informações levadas aos jornalistas com agentes como a PM e outros órgãos estatais.

Em outro caminho, a característica de circularidade na espiral informativa formada pela estrutura de difusão das notícias na programação ao vivo possibilita a ampliação de diferentes vozes na cobertura. O modelo apresentado reforça o potencial da alternância de vozes como uma característica do jornalismo informativo (MEDITSCH, 2001) no atual momento expandido (KISCHINHEVSKY, 2016a) e hipermidiático (LOPEZ, 2010). A construção da notícia radiofônica passa pela seleção de diferentes funções no organograma das redações e pode ser distribuída no radiojornal como um todo e não necessariamente em um momento específico.

A presença de múltiplos pontos de vista, de diferentes opiniões somente traz ao jornalismo a essência de um espaço de disputa social e ideológica entre distintos campos de saber, lugares de fala e sujeitos sociais. O número de violações durante a Intervenção Federal no Rio de Janeiro, de mortes nas comunidades da capital carioca e na baixada, além dos dados que reforçam a insegurança histórica reforçam a necessidade de uma cobertura aprofundada que vocalize as 
reivindicações de quem vive esse cotidiano. A colonização do patrimonialismo, do patriarcado e do capitalismo interfere também na possibilidade de escuta dos subalternizados, mas cabe ao jornalismo buscar equilibrar os homens lentos e rápidos em uma sociedade marcada pela divisão e o estranhamento do outro.

\section{Referências}

ALSINA, Miquel Rodrigo. A construção da Notícia Petrópolis: Vozes, 2009.

BARBOSA, Thiago. Entrevista realizada no dia 13 de agosto de 2018. Rio de Janeiro, 2018.

BARDIN, Laurence. Análise de conteúdo. Lisboa: Edições 70, 1977.

BERGER, P. L., LUCKMANN, T. Modernidade, pluralismo e crise de sentido: a orientação do homem moderno. Petrópolis: Vozes, 2004.

BRUNS, Axel. Gatekeeping, Gatewatching, Realimentação em Tempo Real: novos desafios para o Jornalismo. Brazilian Journalism Research, [s. l.], v. 7, n. 2, 2011. https://doi.org/10.25200/BJR.v7n2.2011.342.

CARPENTIER, Nico. Participation and Interactivity: Changing Perspectives. The Construction of an Integrated Model on Access, Interaction and Participation. In: V. NIGHTINGALE; T. DWYER (ed.). New Media Worlds. Challenges for Convergence. Melbourne: Oxford University Press, 2007. p. 214-230.

CARPENTIER, Nico. The concept of participation. If they have acess and interact, do they really participate? Revista Fronteiras: Estudos Midiáticos, [s. l.], v. 14, n. 2 , maio/ago. 2012. https://doi.org/10.4013/fem.2012.142.10.

CASCARDO, Rafaela. Entrevista realizada no dia 18 de agosto de 2018. Rio de Janeiro, 2018.

CHAGAS, L. J. V. A seleção das fontes via WhatsApp no BandNews Rio, $1^{\text {a }}$ edição, e os conceitos de participação, interação e acesso. Novos Olhares, [s. l.], v. 7. p. 53-63, 2018b. https://doi.org/10.11606/issn.2238-7714. no.2018.147190.

CHAGAS, Luãn J. V.. Gatewatching and Collective Curation: Selecting Popular Radio Journalism Sources at Bandnews Rio FM. Brazilian Journalism Research, Is. l.], v. 14, p. 900-917, 2018a. https://doi.org/10.25200/ BJR.v14n3.2018.1080.

CHAPARRO, Manuel Carlos. Pragmática do jornalismo: buscas práticas para uma teoria da ação jornalistica. São Paulo: Summus Editorial, 1994.

DE KEYSER, Jeroen; RAEYMAECKERS, Karin; PAULUSSEN, Steve. Are Citizens Becoming Sources? A Look into the Professional Contacts of Flemish Journalists. In: FRANKLIN, Bob; CARLSON, Matt (org.). Journalists, sources and credibility. Londres: Routledge, 2011.
ELİAS, Carlos. Adaptación de la metodología de "observación participante" al estudio de los gabinetes de prensa como fuentes periodisticas. Empiria: Revista de Metodología de Ciencias Sociales, Madrid, n. 6, 2003. https://doi.org/10.5944/empiria.6.2003.938.

FRANKLIN, Bob. Sources, credibility and the continuing crisis of UK journalism. In: FRANKLIN, Bob; CARLSON, Matt (org.). Journalists, sources and credibility. Londres: Routledge, 2011. https://doi. org/10.4324/9780203835708.

GANS, Herbert J. Deciding what's news: a study of CBS Evening News, NBC Nightly News, Newsweek and Time. New York: Vintage, 1980.

GASKEL, G. Entrevistas individuais e grupais. In: BAUER, M. W:; GASKEL, G. (org.). Pesquisa qualitativa com texto, imagem e som: um manual prático. Tradução de Pedrinho A. Guarechi. Petrópolis: Vozes, 2002.

GIL, Antônio Carlos. Métodos e técnicas de pesquisa social. 6. ed. São Paulo: Atlas, 2008.

HALL, Stuart et al. A produção social das notícias: o mugging nos mídia. In: TRAQUINA, Nelson (org.). Jornalismo: questões, teorias e "estórias". Lisboa: Vega, 1999.

HERSCOVITZ, Heloiza Golbspan. Análise de Conteúdo em Jornalismo. In: LAGO, Cláudia; BENEETTI, Márcia (org.). Metodologia de Pesquisa em Jornalismo. Petrópolis: Editora Vozes, 2007.

KISCHINHEVSKY, Marcelo. Métodos de pesquisa qualitativa aplicada à comunicação radiofônica. In: MOURA, Cláudia Peixoto de; LOPES, Maria Immacolata Vassallo de (org.). Pesquisa em Comunicação: metodologias e práticas acadêmicas. Porto Alegre: EDIPUCRS, 2016b. https://doi.org/10.1590/1982-2554233396.

KISCHINHEVSKY, Marcelo. Rádio e mídias sociais mediações e interações radiofônicas em plataformas digitais de comunicação. Rio de Janeiro: Mauad X, 2016a.

KISCHINHEVSKY, Marcelo; CHAGAS, Luãn. Diversidade não é igual a pluralidade - Proposta de categorização das fontes no radiojornalismo. Galáxia: Revista do Programa de Pós-Graduação em Comunicação e Semiótica, [s. l.], v. 1, n. 36, dez. 2017.

LOPEZ, Débora Cristina. Radiojornalismo hipermidiático: tendências e perspectivas do jornalismo de rádio all news brasileiro em um contexto de convergência tecnológica. Covilhã: UBI/LabCom Books, 2010.

MANNING, Paul. News and News Sources: A Critical Introduction. Londres: Sage, 2001.

MEDITSCH, Eduardo. O Rádio na Era da Informação Teoria e técnica do novo radiojornalismo. Florianópolis: Insular, 2001.

Media Kit "Somos CBN". Disponivel em: https://anunciesgr.globo.com/cbn/documentos/midia-kit.pdf. Acesso em: 23 maio 2020.

MOLOTCH, Harvey; LESTER, Marilyn. A notícia como procedimento intencional: acerca do uso estratégico de acontecimentos de rotina, acidentes e escândalos. In: TRAQUINA, Nelson (org.). Jornalismo: questões, teorias e "estórias". Lisboa: Vega, 1999. 
NEVEU, Érick. Sociologia do jornalismo. São Paulo: Loyola, 2006

O'NEILL, Deirdre; O'CONNOR, Catherine. The passive journalist: how sources dominate local news. Journalism Practice, Londres, v. 2, n. 3, 2008. https://doi. org/10.1080/17512780802281248.

PATHERSON, C. Why ethnography? In: PATHERSON, C.; DOMINGO, D. (org.). Making online news: the ethnography of new media production. New York: Peter Lang, 2008

PINTO, Manuel. Fontes jornalísticas: contributos para o mapeamento do campo. Comunicação e Sociedade. Braga, Universidade do Minho, v. 14, n. 1-2, p. 277-294, 2000. https://doi.org/10.17231/comsoc.2(2000).1401.

PORTO, Mauro. Mídia e deliberação política: o modelo do cidadão interpretante. Política e Sociedade, [S. l.], n. 2, p. 67-108, 2003.

PORTO, Ricardo. Entrevista realizada no dia 17 de agosto de 2018. Rio de Janeiro, 2018.

QUIJANO, Anibal. Nota sobre o conceito de marginalidade social. In: PEREIRA, L. (org.), Populações marginais São Paulo: Duas Cidades, 1978. p. 11-72.

REICH, Zvi. Source Credibility as a Journalistic Work Tool. In: FRANKLIN, Bob; CARLSON, Matt (org.). Journalists, sources and credibility. Londres: Routledge, 2011.

$\mathrm{REICH}, \mathrm{Zvi}$. Why citizens still rarely serve as news sources: validating a tripartite model of circumstantial, logistical, and evaluative barriers. International Journal of Communication, [s. l.], v. 9, 2015

RODRIGUES, Rute Imanishi; ARMSTRONG, Karolina. A Intervenção Federal no Rio de Janeiro e as organizações da sociedade civil. Rio de Janeiro: Ipea - Instituto de Pesquisa Econômica Aplicada, 2019

SANT'ANNA, Francisco. Midia das fontes: um novo ator no cenário jornalístico brasileiro: um olhar sobre a ação midiática do Senado Federal. Brasília, DF: Senado Federal, Subsecretaria de Edições Técnicas, 2009.

SANTOS, Bianca. Entrevista realizada no dia 17 de agosto de 2018. Rio de Janeiro, 2018.

SANTOS, Boaventura de Souza. Para uma sociologia das ausências e das emergências. Revista Crítica de Ciências Sociais, [s. l.], 63, p. 237-280, 2002. https:// doi.org/10.4000/rccs.1285.

SANTOS, Milton. A natureza do espaço: técnica e tempo, razão e emoção. 4. ed. São Paulo: Editora USP, 2006.

SCHMITZ, Aldo A. Fontes de notícias: ações e estratégias das fontes no jornalismo. Florianópolis: Combook, 2011.

SHOEMAKER, Pamela J., VOS, Tim P. Teoria do gatekeeping: seleção e construção da notícia. Porto Alegre: Editora Penso, 2011

SOLEY, L. W. The news shapers: the sources who explain the news. New York: Praeger Publishers, 1992.
SPIVAK, Gayatri Chakravorty. Pode o subalterno falar? Tradução Sandra Regina Goulart Almeida; Marcos Pereira Feitosa; André Pereira. Belo Horizonte: Editora da UFMG, 2010

TRAQUINA, Nelson. Teorias do jornalismo: Por que as notícias são como são. Vol. 1. Florianópolis: Insular, 2005.

TRIVIÑOS, Augusto N. S. Introdução à pesquisa em ciências sociais. São Paulo: Editora Atlas, 1987.

\section{Luãn José Vaz Chagas}

Doutor pelo Programa de Pós-Graduação em Comunicação da Universidade do Estado do Rio de Janeiro (UERJ), no Rio de Janeiro, RJ, Brasil; professor do Programa de Pós-Graduação em Comunicação (PPGCOM) e da Faculdade de Comunicação e Artes da Universidade Federal de Mato Grosso (UFMT), em Cuiabá, MT, Brasil.

\section{Endereço para correspondência}

Luãn José Vaz Chagas

Universidade Federal de Mato Grosso

Faculdade de Comunicação e Artes

Rua Quarenta e Nove, 2367

Boa Esperança, 78060900

Cuiabá, MT, Brasil 